\title{
Incorporation of layered double nanomaterials in thin film nanocomposite nanofiltration membrane for magnesium sulphate removal
}

\author{
Muhammad Hanis Tajuddin ${ }^{1,2,}$, Norhaniza Yusof ${ }^{1,2, *}$, Wan Norharyati Wan Salleh ${ }^{1,2}$, \\ Ahmad Fauzi Ismail ${ }^{1,2}$ Nur Hanis Hayati Hairom ${ }^{3}$, and Nurasyikin Misdan ${ }^{3}$ \\ ${ }^{1}$ Advanced Membrane Technology Research Centre (AMTEC), Universiti Teknologi Malaysia, \\ 81310 Skudai, Johor Bahru, Malaysia \\ ${ }^{2}$ Faculty of Chemical and Energy Engineering (FCEE), Universiti Teknologi Malaysia, 81310 \\ Skudai, Johor Bahru, Malaysia \\ ${ }^{3}$ Faculty of Engineering Technology, Universiti Tun Hussein Onn Malaysia, 86400 Parit Raja, Johor \\ Malaysia
}

\begin{abstract}
Thin film nanocomposite (TFN) membrane with copperaluminium layered double hydroxides (LDH) incorporated into polyamide (PA) selective layer has been prepared for magnesium sulphate salt removal. $0,0.05,0.1,0.15,0.2 \mathrm{wt} \%$ of $\mathrm{LDH}$ were dispersed in the trimesoyl chloride (TMC) in n-hexane as organic solution and embedded into PA layer during interfacial polymerization with piperazine. The fabricated membranes were further characterized to evaluate its morphological structure and membrane surface hydrophilicity. The TFN membranes performance were evaluated with divalent salt magnesium sulphate $\left(\mathrm{MgSO}_{4}\right)$ removal and compared with thin film composite (TFC). The morphological structures of TFN membranes were altered and the surface hydrophilicity were enhanced with addition of LDH. Incorporation of LDH has improved the permeate water flux by $82.5 \%$ compared to that of TFC membrane with satisfactory rejection of $\mathrm{MgSO}_{4}$. This study has experimentally validated the potential of LDH to improve the divalent salt separation performance for TFN membranes.
\end{abstract}

\section{Introduction}

Significant growth in population and economy have increased the demand of clean water which led to water shortage specifically in water-stressed region areas. To improve the current technologies, the search for potential advanced materials has gained significant attraction among researchers to cope with clean water demand.

The current commercial of nanofiltration membrane are dominated by polyamide thin film composite (TFC) membrane. With the performance and characteristics pores lies between ultrafiltration and reverse osmosis, nanofiltration (NF) process have high retention

\footnotetext{
* Corresponding author: norhaniza@petroleum.utm.my
} 
flux, relatively low operating pressure and high rejection towards multivalent salts [1-3]. However one of the major drawbacks of TFC membrane is susceptibility towards fouling thus rendering their overall performances.

Thin film nanocomposite (TFN) membrane incorporated with nanomaterials is gaining significant attention since its first introduction in 2007 by Lee Hoek [4]. It is believed that incorporation of nanomaterials would play an important role in improving membrane properties such as hydrophilicity, selectivity and water permeability [4-5]. In recent years many nanoparticles have been utilized in fabrication of TFN membranes, including zeolites $[7,8,9] \mathrm{TiO}_{2}[10], \mathrm{Ag}, \mathrm{CNTs}$ and silica [5]. Furthermore, incorporation of nanomaterials into thin film structures has significantly improved the performances of available composite nanofiltration membrane and reverse osmosis membranes.

In recent years, layered materials as illustrated in Fig. 1 such as layered double hydroxides has gained significant attention especially in membrane fabrication for desalination process [10-11]. With their ability to intercalated in interlayer regions and tunable ratio composition they were found prominently in many applications such as photocatalyst, adsorbents and medicines. Example of layered compounds are layered transition mixed metal oxides, layered hydroxide salts and layered double hydroxides. LDHs have general formula of $\left[\mathrm{M}(\mathrm{II})_{1-\mathrm{x}} \mathrm{M}(\mathrm{III})_{\mathrm{x}}(\mathrm{OH})_{2}\right]^{\mathrm{x}+}\left[\left(\mathrm{A}^{\mathrm{n}-}\right)_{\mathrm{x} / \mathrm{n}} \cdot \mathrm{yH}_{2} \mathrm{O}\right]$, where $\mathrm{M}(\mathrm{II})$ and $\mathrm{M}(\mathrm{III})$ represents divalent $(\mathrm{Mg}, \mathrm{Zn}, \mathrm{Co}, \mathrm{Cu}, \mathrm{Ni})$ and trivalent cations $(\mathrm{Al}, \mathrm{Fe}, \mathrm{Ga}) . \mathrm{A}^{\mathrm{n}-}$ is an interlayer anion such as $\mathrm{Cl}^{-}, \mathrm{SO}_{4}{ }^{2-}$ or $\mathrm{CO}_{3}{ }^{2-}$ etc. and the $\mathrm{x}$ value is between 0.2-0.33 can be describe as molar ratio between $\mathrm{M}(\mathrm{II}) /[\mathrm{M}(\mathrm{III})+\mathrm{M}(\mathrm{III})]$ [13].

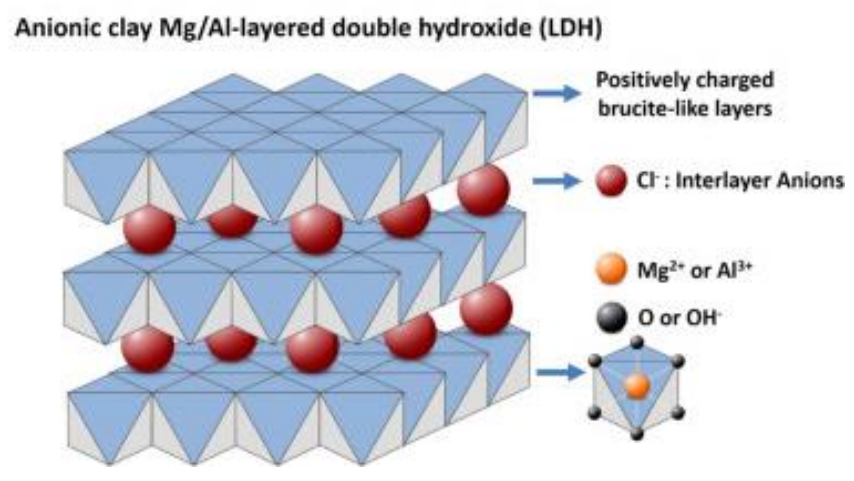

Fig. 1. Schematic diagram of LDH structures [11].

Therefore, this study aimed to synthesize a new type of thin film nanocomposite by incorporating layered double hydroxides into polyamide selective layer which was formed on top of polysulfone substrate. The physicochemical properties of as prepared $\mathrm{Cu}-\mathrm{Al}$ LDHs were evaluated in term of its morphological structures. The influences of LDHs were systematically investigated through its effect in membrane morphology, surface hydrophilicity and separation performances of $\mathrm{MgSO}_{4}$ salts.

\section{Materials and methods}

\subsection{Materials}

Aluminium nitrate nonahydrate $\mathrm{Al}\left(\mathrm{NO}_{3}\right)_{2} .9 \mathrm{H}_{2} \mathrm{O}$ and copper (II) nitrate trihydrate $\mathrm{Cu}\left(\mathrm{NO}_{3}\right)_{2} \cdot 3 \mathrm{H}_{2} \mathrm{O}$ powder were purchased from Sigma Aldrich and Merck respectively. Sodium hydroxide $(\mathrm{NaOH})$ and sodium carbonate $\left(\mathrm{Na}_{2} \mathrm{CO}_{3}\right)$ was obtained from from 
Sigma Aldrich and Qrec respectively. All the chemicals were of analytical grade and used without further purification. Commercial PSf pellets purchased from BASF SE Germany is the main component in membrane fabrication. Polyvinlypyrolidone ( $\mathrm{MW}=40,000 \mathrm{~g} / \mathrm{mol}$ ) supplied by Sigma Aldrich as pore forming agent. For the preparation of ultra-thin PA layer, piperazine (PIP) and 1,3,5 - benzene tricarboxylic acid chloride or trimesoyl chloride (TMC) were obtained from Sigma Aldrich. N-methyl-2-pyrollidone (NMP) (Purity > 99.5\%) obtained from Sigma Aldrich and used as a solvent for the preparation of substrate membrane. $n$-hexane (purity $>99.5 \%$ ) will be used as organic solvent for TMC monomer, were purchased from Merck. For membrane performance, $\mathrm{MgSO}_{4}$ by Sigma Aldrich was used to prepare aqueous salt solution for membrane flux and rejection determination.

\subsection{Synthesis of LDH}

Firstly, $\mathrm{Cu}(\mathrm{OH})_{2}$ was precipitated by adding $100 \mathrm{ml}$ of $0.2 \mathrm{~mol} / \mathrm{L} \mathrm{NaOH}$ into $100 \mathrm{ml}$ of 0.1 $\mathrm{mol} / \mathrm{L} \mathrm{Cu}\left(\mathrm{NO}_{3}\right)_{2}$ solution. Then, the precipitate of $\mathrm{Cu}(\mathrm{OH})_{2}$ was added into $100 \mathrm{ml}$ of 0.05 $\mathrm{mol} / \mathrm{L} \mathrm{Al}\left(\mathrm{NO}_{3}\right)_{2}$ solution under vigorous stir for $60 \mathrm{~min}$. The $\mathrm{pH}$ was adjusted until $\mathrm{pH} 12$ by using $1 \mathrm{M}$ of $\mathrm{NaOH}$ solution. The precipitates were aged at $6 \mathrm{~h}$ and separated by centrifuge at $7000 \mathrm{rpm}$ and washed with deionized water several times. Finally, the obtained precipitates was dried at $60^{\circ} \mathrm{C}$ for $24 \mathrm{~h}$.

\subsection{Preparation of thin film nanocomposite membrane}

An appropriate amount of $\mathrm{Cu}-\mathrm{Al} \mathrm{LDH}$ was added in $20 \mathrm{ml}$ of $0.1(\mathrm{w} / \mathrm{v}) \% \mathrm{TMC}$ in $\mathrm{n}$-hexane and dispersed via ultrasonicating for 1 hour. Firstly, the substrate was clamped in between glass plate and silicone rubber. Then, $20 \mathrm{ml}$ of $2(\mathrm{w} / \mathrm{v}) \%$ PIP aqueous solution was poured on top of PSf substrate for $2 \mathrm{~min}$. After that, the excess PIP solution on the surface of substrate membrane was removed by rubber roller. Then, $20 \mathrm{ml}$ of $0.1(\mathrm{w} / \mathrm{v}) \%$ TMC in $\mathrm{n}$ hexane solution was poured onto substrate for $1 \mathrm{~min}$ and polyamide layer was instantaneously form. Subsequently, the membrane was stored in oven at $60^{\circ} \mathrm{C}$ for $5 \mathrm{~min}$, the resultant membrane rinsed with DI water and stored in deionized water before used. The protocol of preparation composite membrane was illustrated in Figure 3.2. The amount of $\mathrm{Cu}-\mathrm{Al} \mathrm{LDH}$ concentration were varied from $0,0.05,0.1,0.15$ to $0.2(\mathrm{w} / \mathrm{v}) \%$. The resulting membrane was denoted as TFC, TFN 0.05 , TFN 0.1 , TFN 0.15 and TFN 0.2.TFC membrane without $\mathrm{Cu}-\mathrm{Al} \mathrm{LDH}$ was prepared to serve as a control in this experiment.

\subsection{Characterization of Cu-AI LDH nanoparticles, TFC and TFN membranes}

Different SEM micrographs with various magnifications were obtained from cross section, skin layer thickness and surface of TFC/TFN membrane and LDH nanoparticles by using scanning electron microscopy (Model: TM 3000, Hitachi). LDH nanofillers were characterized by Transmission Electron Microscopy (TEM) (Orius SC 1000A) to observe their particle properties. Meanwhile, surface hydrophicility of TFC and TFN was analysed by contact angle meter (Dataphysics OCA 15pro).

\subsection{Membrane separation performances}

The flux and rejection of fabricated TFC and TFN membranes was assessed by using deadend filtration system (Sterlitech ${ }^{\mathrm{TM}}$ HP4750 Stirred Cell) under nitrogen atmosphere. The effective surface are of the membrane is $14.6 \mathrm{~cm}^{2}$. The TFC and TFN membranes were compacted at a pressure 8 bar for about $30 \mathrm{~min}$ to achieve flux steady state condition. The 
experiments will be performed by using $1000 \mathrm{ppm}$ of $\mathrm{MgSO}_{4}$ solution at operating pressure and temperature set at 7 bar and $25 \mathrm{C}$ respectively. Membrane water flux $(F)$ will be subsequently measured by using the following equation:

$$
F=\frac{V}{t \times A}
$$

where $\mathrm{V}$ is the permeate volume in litre $(\mathrm{L}), \mathrm{A}$ is the membrane area $\left(\mathrm{m}^{2}\right)$ and $t$ is the experimental time to obtain $V(\mathrm{~h})$. The salt concentration in the feed and permeate solutions will be measured by bench conductivity meter (Jenway 4520). The membrane salt rejection will be determined by using the following equation:

$$
\mathrm{R}(\%)=\left(1-\frac{C_{p}}{C_{f}}\right) \times 100
$$

where $C_{p}$ is the permeate concentration (ppm) and $C_{f}$ is the feed concentration (ppm) respectively.

\section{Results and discussions}

\subsection{LDH morphological structures}

From the morphological structures showed in TEM images in Fig. 2 a) and b), LDH nanofillers displayed a layer structure materials as indicated in square red line. This characteristics properties were found as similar as shown by research reported from Dong and co-workers [11]. Besides that, the SEM images of LDH nanofillers shows that the CuAl LDH particles cluster all together as shown in red circle in figure 2 c) into a large aggregates mainly caused by high surface charge and surface tension $[11,13]$.

\subsection{Effects of LDH on membrane properties}

The top surface of TFN membrane morphologies are presented in Fig. 3. Fig. 3 (a) show typical poly(piperazine amide) with a rough surface and firmly grab globules. These traits can be seen similarly found in research reported by [15]. However after addition of LDH nanofillers, the surface become smoother compared with pristine TFC and red circle in Fig. 4 (b), (c), (d), (e) indicating the presence of LDH in selective layer. Generally, incorporation of hydrophilic materials reduce surface roughness of membrane with similar behaviour was observed when Zarrabi et al. [16] embedded amine functionalized MWCNT. 

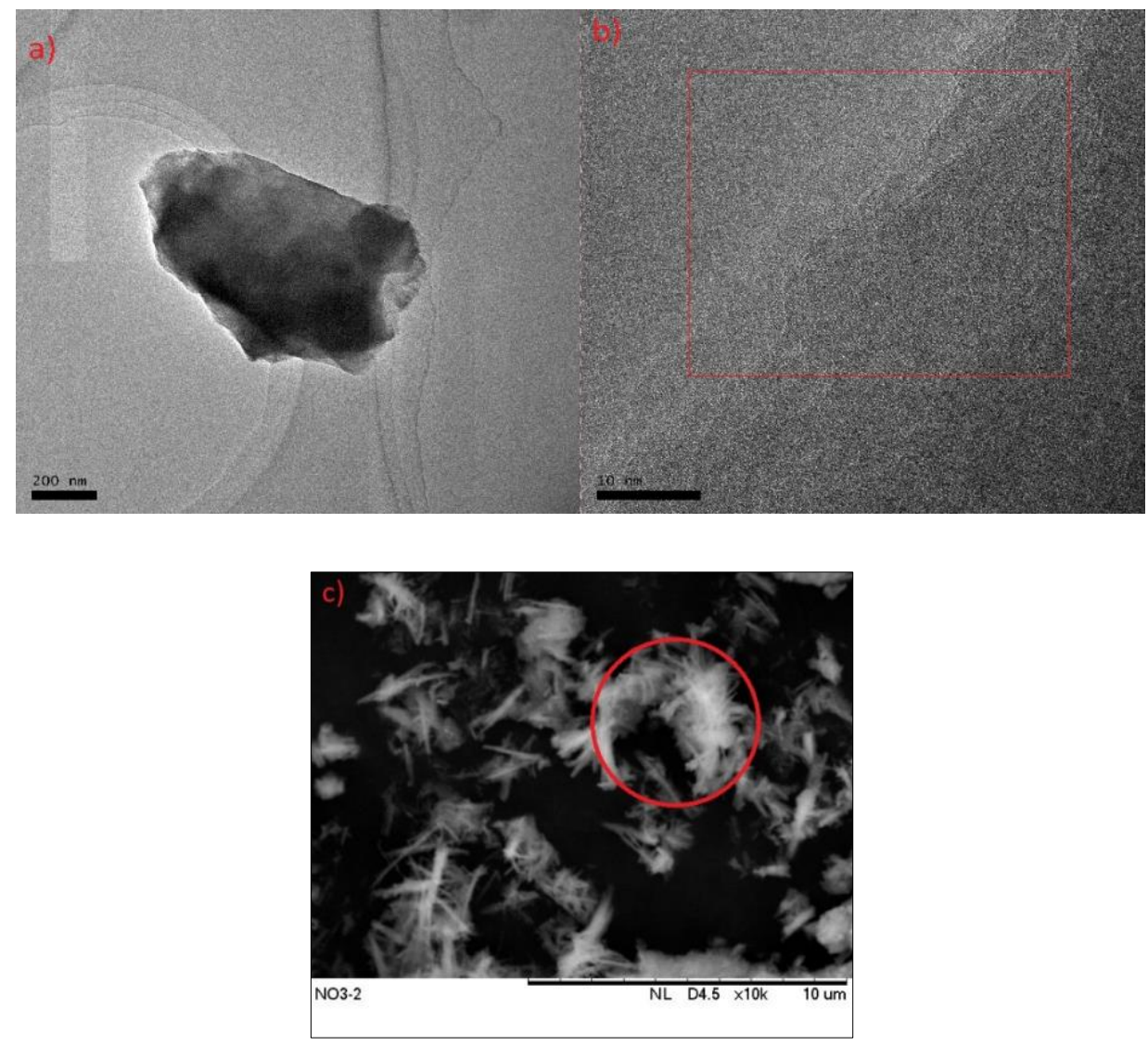

Fig. 2. a) and b) TEM displayed the irregular shape of LDH c) SEM images of synthesized LDH nanofillers.

Fig. 4 presented cross section image of poly(piperazine amide) thin film membrane. According to the cross section images, the red line in Fig. 4 (b) indicating the formation of dense selective layer in thin film composite membranes. These traits were further supported by Fig. 4 (c) shows the thickness of poly (piperazine amide) layer with measurement of averagely ranging from $246 \mathrm{~nm}$ to $294 \mathrm{~nm}$. The same features also displayed by Wang and co-researchers when they were fabricating thin film composite nanofiltration membranes [17].

The water contact angle of TFC and TFN membranes are presented in Fig. 5. From the Fig. 5, it can be observed that pristine TFC displayed high contact angle of $53.24^{\circ}$. Moreover, after the incorporation of nanofillers into polyamide layer, the contact angle values decreased as the amount of LDH loadings increased from $0.05 \mathrm{wt} \%$ ( $48.64^{\circ}$ ) to 0.2 (37.50) $\mathrm{wt} \%$ indicated the improvement in membrane hydrophilicity. This improvement of membrane hydrophilicity could be ascribed by hydrophilic property and presence of hydroxyls group in LDH nanofillers. Another reported research by Xia et al [18] show the same improvement in membrane hydrophilicity as they incorporated nanofillers in polyamide membrane. Furthermore, the hydrophilic surface membrane are favourable in desalination process because it could produce better water permeability and fouling resistance $[10,17]$. 

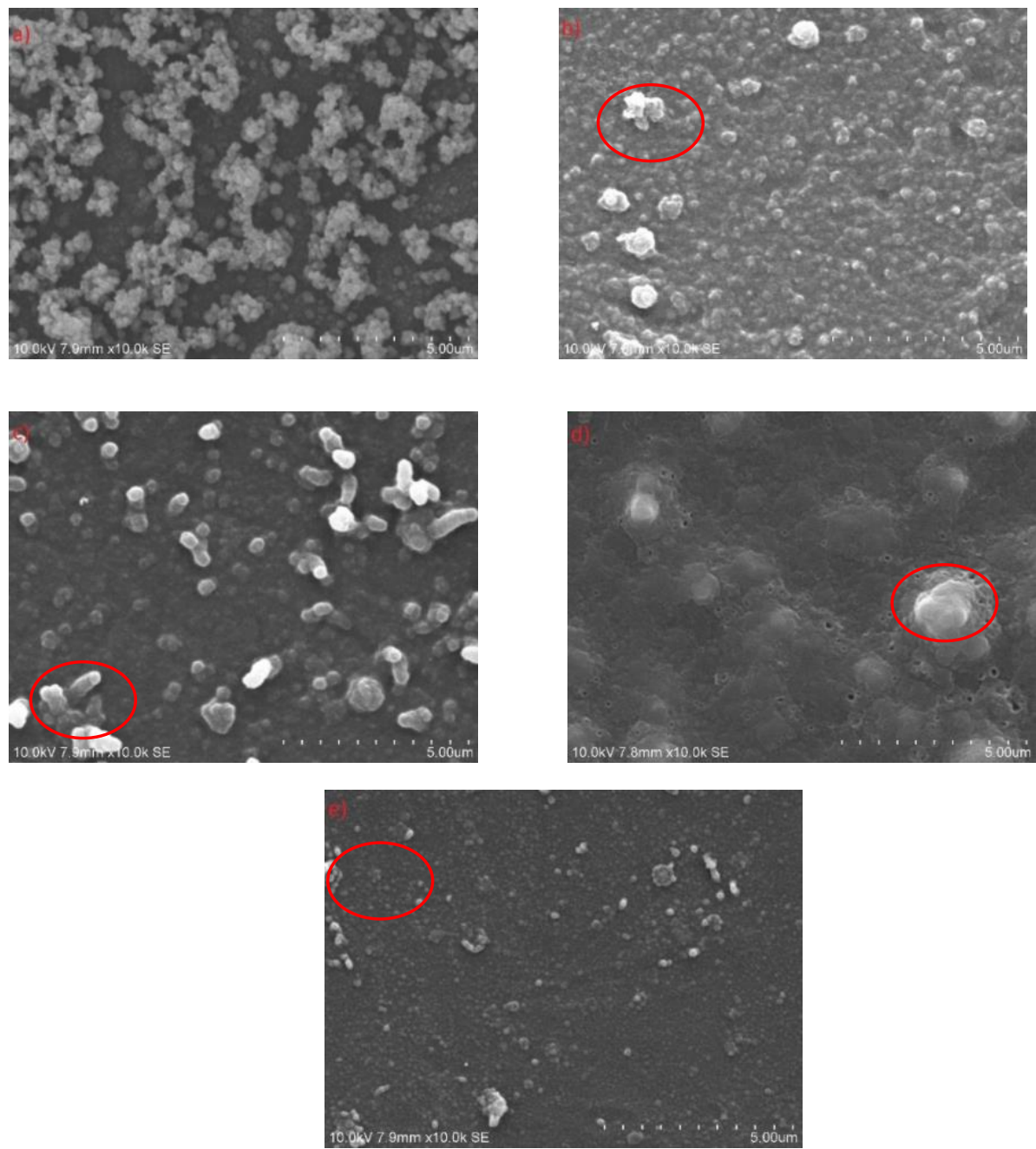

Fig. 3. SEM images of a) TFC b) TFN 0.05 c) TFN 0.1 d) TFN 0.15 and e) TFN 0.2 membrane shows the appearance of LDH on top of the polyamide layer.

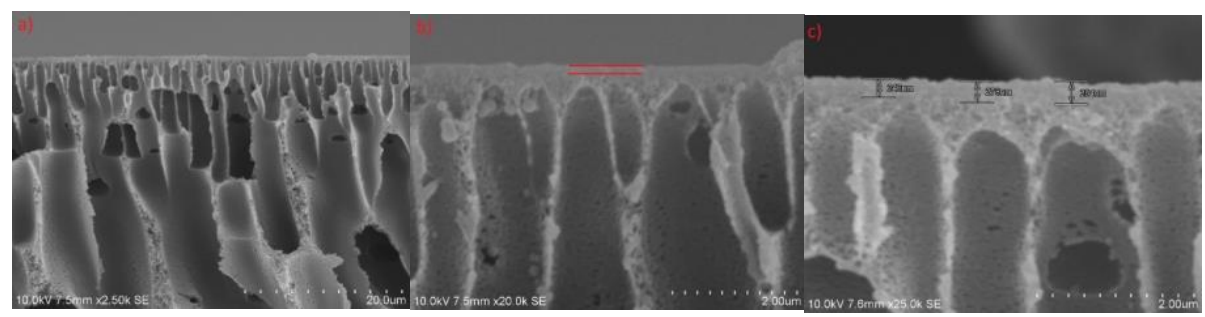

Fig. 4. Cross section image of poly(piperazine amide) membrane a) 2500k magnification b) 20000k magnification c) $25000 \mathrm{k}$ magnification. 


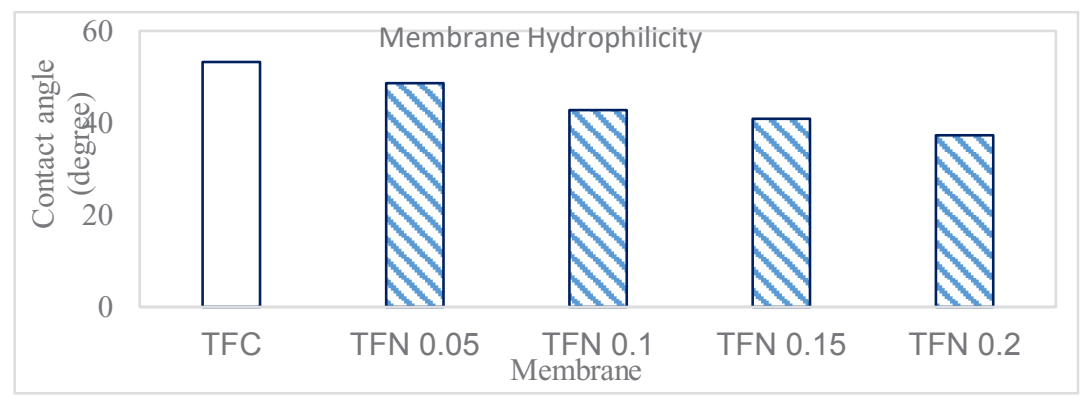

Fig. 5. Membrane surface hydrophilicity.

\subsection{Membrane separation performances}

The separation performance of TFC and TFN membranes were evaluated by using $\mathrm{MgSO}_{4}$ a representative of divalent salts. The applied pressure of 7 bar was applied to TFC and TFN membrane and were examined in term of water permeability and $\mathrm{MgSO}_{4}$ rejection as shown in Fig. 6.

The water permeability of TFC, TFN 0.05 , TFN 0.1 , TFN 0.1 and TFN 0.2 membrane under the studied condition of 7 bar were recorded at 1.32, 1.75, 3.23, 5.57 and 7.50 $\mathrm{LMH} /$ Bar respectively. The significant improvement of water permeability from TFC to TFN probably caused by incorporation of LDH nanoparticles into polyamide layer. Moreover, the notably increased of water permeability are correlated to membrane hydrophilicity as stated in figure 5 . with significant increment by $82.4 \%$. As the values of contact angle measurement was decreased the hydrophilicity of membrane improved due to existence of layered structure of LDH nanofillers [11-12].

Meanwhile the MgSO4 salt rejection of LDH-polyamide membrane for TFC, TFN 0.05 , TFN 0.1, TFN 0.1 and TFN 0.2 were recorded at $91.23 \%, 93.63 \%, 95.41 \%, 94.01 \%$ and $90.57 \%$. At the $0.1 \mathrm{wt} \%$ of $\mathrm{LDH}$, the TFN membrane displayed the best separation performance with consideration of high water permeability $\left(3.23 \mathrm{~L} / \mathrm{m}^{2}\right.$.h.bar $)$ and salt rejection $(95.41 \%)$ with slight improvement of $4.18 \%$ compared with pristine TFC membrane. However, the decrease of salt rejection was observed with increment of loading at $0.15 \mathrm{wt} \%$ and $0.2 \mathrm{wt} \% \mathrm{LDH}$ into polyamide layer. It could be mainly attributed to agglomeration of $\mathrm{LDH}$ in the selective layer thus decreasing the rejection as represented in SEM image in Fig. 3.

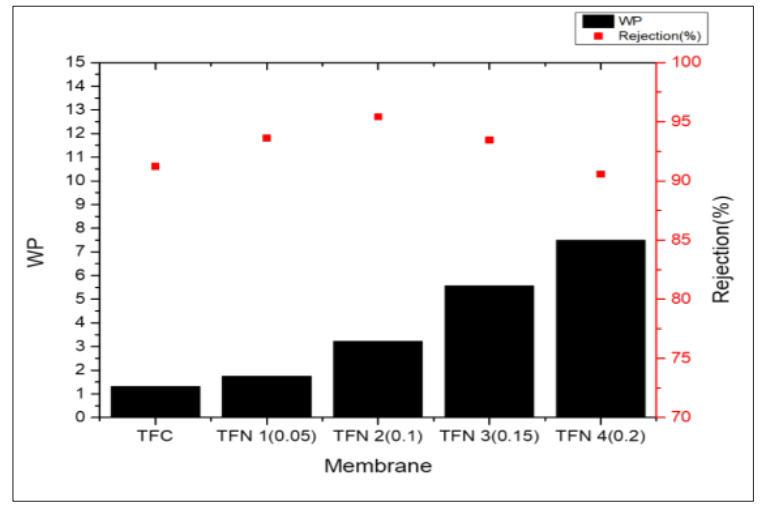

Fig. 6. Water permeability and $\mathrm{MgSO}_{4}$ rejection. 


\section{Conclusions}

TFN membrane incorporated with LDH have been developed for salt removal. The presence of LDH in polyamide layer has altered the properties of membrane and increased the membrane hydrophilicity. Moreover, the water permeability of TFN membrane has significantly improved by $82.4 \%$ compared with pristine TFC. Furthermore, the optimum condition of $\mathrm{MgSO}_{4}$ rejection is displayed by $0.1 \mathrm{wt} \%$ of $\mathrm{LDH}$ in selective layer. Despite having higher rejection at $95.41 \%$ as the loadings were increased mainly cause by the agglomeration of nanofillers in selective layer of membrane. Since the modification of pristine membrane enhanced the water permeability and selectivity, we believed this facile approach can offer another potential materials for improvement in desalination process.

The authors would like to acknowledge the financial support from the Ministry of Higher Education Malaysia and Universiti Teknologi Malaysia under Fundamental Research Grant Scheme (R.J130000.7846.4F929), GUP grant (Q.J130000.2546.16H29), and Higher Institution Centre of Excellence (HiCOE) grant (R.J090301.7846.4J180) and (R.J090301.7846.4J179). The authors would also like to acknowledge the technical and management support from Research Management Centre (RMC), Universiti Teknologi Malaysia.

\section{References}

1. S. Pourjafar, A. Rahimpour, M. Jahanshahi, J. Ind. Eng. Chem. 18, 1398-1405 (2012).

2. M. Liu, Y. Zheng, S. Shuai, Q. Zhou, S. Yu, C. Gao, Desalination 288, 98-107 (2012).

3. B. Rajaeian, A. Rahimpour, M.O. Tade, S. Liu, Desalination. 313, 176-188 (2013).

4. J. Yin, B. Deng, J. Memb. Sci. 479, 256-275 (2015).

5. S. Al Aani, C.J. Wright, M.A. Atieh, N. Hilal, (2016) (to be published).

6. M. Fathizadeh, A. Aroujalian, A. Raisi, J. Memb. Sci. 375, 88-95 (2011).

7. N. Ma, J. Wei, R. Liao, C.Y. Tang, J. Memb. Sci. 405-406, 149-157 (2012).

8. L.X. Dong, X.C. Huang, Z. Wang, Z. Yang, X.M. Wang, C.Y. Tang, Sep. Purif. Technol. 166, 230-239 (2016).

9. E. Bet-moushoul, Y. Mansourpanah, K. Farhadi, M. Tabatabaei, Chem. Eng. J. 283, 29-46 (2015).

10. H. Dong, L. Wu, L. Zhang, H. Chen, C. Gao, J. Memb. Sci. 494, 92-103 (2015).

11. P. Lu, S. Liang, L. Qiu, Y. Gao, Q. Wang, J. Memb. Sci. 504, 196-205 (2016).

12. M.A. Djebbi, M. Braiek, P. Namour, A. Ben Haj Amara, N. Jaffrezic-Renault, Appl. Surf. Sci. 386, 352-363 (2016).

13. N.S. Ahmed, R. Menzel, Y. Wang, A. Garcia-Gallastegui, S.M. Bawaked, A.Y. Obaid, S.N. Basahel, M. Mokhtar, J. Solid State Chem. 246, 130-137 (2017).

14. P. Wen, Y. Chen, X. Hu, B. Cheng, D. Liu, Y. Zhang, S. Nair, J. Memb. Sci. 535, 208-220 (2017).

15. H. Zarrabi, M.E. Yekavalangi, V. Vatanpour, A. Shockravi, M. Safarpour, Desalination. 394, 83-90 (2016).

16. C. Wang, Z. Li, J. Chen, Z. Li, Y. Yin, L. Cao, Y. Zhong, H. Wu, J. Memb. Sci. 523, 273-281 (2017).

17. S. Xia, L. Yao, Y. Zhao, N. Li, Y. Zheng, Chem. Eng. J. 280, 720-727 (2015).

18. E.M. Vrijenhoek, S. Hong, M. J. Memb. Sci. 188, 115-128 (2001). 